\section{Nuclear war models}

SIR - Our study of frost rings as indicators of climatically effective volcanic eruptions (Nature 307, 121; 1984) was discussed by John Maddox in the same issue (p.107) in the context of recent calculations modelling the long-term consequences of nuclear war. We appreciate his synopsis of our study but we do not necessarily agree with his conclusions on the applicability of the frost ring-eruption relationship to the "nuclear winter" question. Mr Maddox emphasized the formation of a frost ring as evidence of a short-lived climatic response to a major eruption and contrasted this seemingly moderate reaction to an atmospheric aerosol veil with the severe picture presented in the nuclear winter scenario, attributing the disparity between the two responses to the nature of the assumptions made about the quantities of dust carried into the stratosphere.

Frost rings are most likely to form at the end of a summer that is already notably or even abnormally cool. Cold delays the completion of cambial activity, rendering the tree more vulnerable to damage by late summer polar-air outbreaks, which occur while the tree is still growing. This suggests not only a short-term regional climatic response, in the form of an unusual incursion of cold air over a period of a few days in years following a major eruption, but also reflects a longer-term response of general cooling - an extreme example of which seems to have occurred in the NorthAtlantic sector in the "year without a summer", following the eruption of Tambora in 1815. If a single point source of atmospheric aerosols injected into the stratosphere can have such significant apparent short-term and long-term effects on climate, as well as a characteristic biological response, we believe the implications for the response to global nuclear war are grave indeed.

Nevertheless, the volcano-climate link is appropriate as an analogue for only that portion of the nuclear-war scenario that occurs as a result of large amounts of dust and aerosols reaching the stratosphere . One should indeed expect a large disparity between the respective responses of the climate system to the aftermath of a major volcanic eruption and the aftermath of a global nuclear war, as the former is a reaction to conditions primarily in the lower stratosphere while the latter is likely to be a far more complex response to conditions through several layers of the entire atmosphere, the most important of which is probably cooling due to heavy concentrations of soot and smoke in the mid-troposphere. Mr Maddox seems to have missed the essential point repeatedly made by Turco et al. that smoke, because of its high absorption in the visible light range and low absorption in the infra-red, causes most of the surface cooling.

Thus the "Krakatoa effect" - namely, a climatic and biological response to an eruption's aerosol veil - certainly supports the likelihood of a similar effect a nuclear war, but that the volcano-climate relationship alone is not wholly analogous to the far more complex and much more severe climatic and biological responses that Turco et al. (Science 222, 1283; 1983), Ehrlich et al (Science 222, 1293; 1983) and Covey et al. (Nature 308, 21; 1984) have postulated. VALMORE C. LAMARCHE JR Laboratory of Tree Ring Research,

The University of Arizona, Tucson, Arizona 85721, USA

KATHERINE K. HiRSCHBOECK

Department of Geography,

University of Oklahoma, Norman, Iklahoma 73069, USA

- The point of that part of the article complained of was to object that one of the principal references was then still "in preparation" and to assert that predictions of nuclear winter should be regarded as qualitative until more accurate data and calculations are available - Editor, Nature.

\section{Lie detector lies}

SIR - It is illuminating to express the results of studies in the fallibility of lie detection, such as that of Kleinmutz and Szucko' ${ }^{1}$, in terms of the amount of information obtained, which can be measured as the "expected weight of evidence" introduced by I.J. Good" ${ }^{2}$. Doing so reveals that what is obtained is a small fraction of the information required to take any rational decision.

Expressing experimental results as proportions: valid positive: proportion $p$ of all actual liars, valid negative: proportion $q^{\prime}$ of all truth-tellers, false positive: $p^{\prime}=1-q^{\prime}$, false negative: $q=1-p$.

The expected weight of evidence is the expected value of the logarithm of the Bayes' factor, which is

$$
I=p \log \left(p / p^{\prime}\right)+q \log \left(q / q^{\prime}\right)
$$

The logarithms can be taken to any base desired, and I follow Good ${ }^{2}$ in using logarithms to base $10^{0.1}$ and calling the result "decibels" (db). Strictly, due allowance should be made for the small sample size, but for illustration I shall use the crude proportions as quoted by Kleinmutz and Szucko, which will tend to overestimate $I$. The value of $I$ obtained for the results of their six interpreters are $1.3,0.6$, $2.8,2.1,0.8,1.3$, averaging $1.5 \mathrm{db}$ (the variation is probably random rather than a reflection of varying skill). This is a very small amount of information. To make a confident decision in normal circumstances we usually need some $20 \mathrm{db}$ - for instance, if we start with a hypothesis at "evens" (50 per cent probability), a logfactor of $20 \mathrm{db}$, that is a Bayes' factor of 100 , will make it 100 to 1 on $(99.01$ per cent probability), which can perhaps be regarded as “practical certainty". In some pro- posed applications of the lie detector, however, we are starting with an a priori improbable hypothesis - that an apparently honest person is a traitor, for instance. If the prior odds are estimated as 1,000 to 1 against, the log-factor required for practical certainty becomes $50 \mathrm{db}$.

If some procedure can be devised for collecting many independent scraps of information like this and combining them accurately, for instance by estimating credible log-factors and adding them, it might be possible to produce a reliable result. The "guilty knowledge test" "3 which Kleinmutz and Szucko refer to is an attempt to do this: Lykken suggests using 10 to 16 independent items, which might add up to from 15 to $30 \mathrm{db}$. Where only the result of a single lie-detector test is available, the "confirmation" that it provides is so small that the only just course is to disregard it entirely.

30 Coltham $R d$,

Cheltenham, Glos., UK

1. Kleinmutz, B. \& Szucko, J.J. Nature 308, 449-450 (1984).

2. Good. 1.J. Probability and the Weighing of Evidence (Griffin, L.ondon, 1950).

3. L.ykken, D.T. J. appl. Psychol. 44, 258-262 (1960).

\section{Crater dated}

SIR - The cover of your 19 April issue shows an aerial photograph of Meteor Crater, Arizona. It is stated in the caption that the crater is the "result of an impact about 50 million years ago" but I am unaware of any Meteor Crater age estimates of this magnitude. The crater is clearly of Pleistocene age.

The age of Meteor Crater has been estimated using various lines of reasoning. It was observed 50 years ago that sediments at the crater show evidence of the Wisconsin glacial episode'. These soils were later correlated with the well-studied stratigraphy at Hopi Buttes and it was observed that a Pleistocene sediment directly overlies the crater ejecta ${ }^{2}$. Two major pluvial episodes of Pleistocene age are recorded as distinct erosional patterns within the crater ${ }^{3}$.

I have recently applied thermoluminescence (TL) dating to shock-metamorphosed sedimentary rocks from Meteor Crater (in preparation). Meteor Crater can be dated by the TL method because the TL of the target rocks was reset by the high temperatures experienced during the meteorite impact. After cooling, TL reaccumulated due to exposure to natural radioactivity. These measurements indicate that the Meteor Crater impact occurred 49,900 years ago with an estimated uncertainty of 2,900 years.

STEPHEN R. SUTTON

McDonnell Center for the Space Sciences, Washington University, St Louis, Missouri 63130, USA

1. Blackwelder, E. Science 76, 557-560 (1932),

2. Shomaker, E.M in The Solar System (eds Middlehurst \& Kuiper) 301-336 (University of Chicago Press, 1965).

3. Shoemaker, E.M. \& Kieffer, S.W. Guidebook to the Geology of Meteor Crater, Arizona (Center for Meteorite Studies, Tempe, Arizona 1979). 